\title{
Effective Leadership Style of Engineering Managers in the Government Construction Agency: National Irrigation Administration - UPRIIS Division V
}

\author{
John Vincent L. Santos ${ }^{1}$, Rhizza Mae B. Lansangan², Ericka V. Marcos ${ }^{3}$, Noel B. \\ Florencondia $^{4}$, Felicitas S. Cabrera ${ }^{5}$ \\ 1,2,3,4,5 Nueva Ecija University of Science and Technology
}

\begin{abstract}
This research is designed to determine the most utilized and effective leadership style based on the actual practices, preferences of the employees in construction agency. Personnel from several sections (i.e. Maintenance, Operations, Construction) of the National Irrigation Administration - UPRIIS Division V participated in the study, and data were acquired using a survey questionnaire. It consists of 40 questions designed to elicit information regarding leadership styles, performance, and outcomes. These extensive questionnaires were administered to provide context for the leadership style employed by the Engineering Managers of the National Irrigation Administration - UPRIIS Division V. The leadership style under consideration is based on four (4) contingency theories of leadership, namely The Fiedler's Model, Situational Leadership Theory, Path -Goal Theory, and Leadermember exchange (LMX) Theory. The study data was extens ively evaluated, and each question was investigated to generate a successful outcome. The finding showed that the effectiveness of a leadership style is strongly tied to the leader ship style used by immediate leaders and the maturity level of the workforce. Other factors to examine include the workplace environment, current events, the work arrangements used, and the well-being of the personnel.
\end{abstract}

KEYWORDS: Engineering Management, Leadership Management, Leadership Development, Construction Agency.

\section{INTRODUCTION}

The Industrial Age is a historical period characterized by developments in economic and social organization. The move in the industrial age toward recognizing the value of human capital has caused firms and organizations to rethink their approaches to people management. Employees are no longer viewed as a resource whose primary role is to deliver products and services; rather, they are viewed as crucial to an organization's ability to offer excellent services and to continually develop and change (Farzad 2006).

An organization is a system of individuals that work together and its success is determined by the collection of persons, including leaders and subordinates, as well as the amount of work put out by everyone. Many scholars and practitioners have conducted studies to discover ideas about leadership, organizational commitment, and work satisfaction to better understand organizational performance. (Cheng et al. 2003) Daily, leaders, managers, supervisors, and Engineering Managers are assigned with obligations. In addition to this responsibility, management tasks include planning, organizing, leading, and monitoring an organization's actions.

Leadership is a topic that has always piqued people's curiosity. The word conjures up ideas of powerful, energetic men commanding triumphant armies, directing business empires from the tops of dazzling skyscrapers, or charting the fate of nations (Yukl 2002). "Leadership is one of the most seen and least understood phenomena on Earth," writes Burns (Burns 1978). History has been preoccupied with the study of its leaders since the dawn of civilization, and leadership is still a topic of current research. Indeed, leadership is sometimes viewed as central determinant in an institution's endeavor in either success or failure (Bass, 1990).

Leading, as one of the management roles, is directly related to how a manager handles administrative procedures, discipline issues, takes control of a group or organization, and serves as a role model for their subordinates and coworkers. This also boosts morale on both sides of the management and worker if the individuals involved use an effective leadership style when circumstances are adverse, especially amid a pandemic.

The danger of a COVID-19 pandemic has compelled most organizations throughout the world to rely on technology innovation to keep operations running. This approach has resulted in utilization of technology equipment such as mobile phones, laptop computers, and personal computers to support distance or work-fromhome arrangements. The majority of industrial operations have been halted, while employees continue to work from home or at home, depending on the arrangements established by the public government and organization's management.

The National Irrigation Administration is one of the 
government organizations that has been impacted by the pandemic. Which is a government-owned and managed organization that is largely in charge of irrigation development and administration. COVID-19 has had a significant impact on the mentioned organization's site activities; yet, most of these government-owned projects are critical to the post-COVID economic development and recovery. Its completion is now significantly reliant on the successful execution and continuation of the project procedures. The organization's executives play a critical role in guiding people to strive toward their goals regardless of the environment.

As we work through the pandemic, its challenges and opportunities should be embraced and promoted as part of a bigger leadership and strategy, in part because this takes into account varying expectations for administration and management responsibilities. Managers should have the capacity to address the ever-changing working system and deploy an optimal style of leadership in any organizational activity as part of the planned contingencies.

This study have considered the following contingency theories of leadership.

Contingency Theories. The effectiveness of the leader is determined by how well their style of leadership is utilized in different situations. The leader must be able to determine the type of leadership style and scenario in which they can be effective. It is known that "There is no one optimum style of leadership," as stated by one of the models of contingency theory.

The Fiedler Model. The Fiedler Model is the first complete leadership contingency model. Based on the concept, successful leadership and organizational performance are dependent on a good fit between the leader's style and the capacity of the leader to control the situation. The Fiedler Model posits that a person's leadership style is predetermined. This means that if a scenario calls for a taskfocused leader and the one in charge is relationship-focused, then the situation must be adjusted or the leader must be replaced.

Situational Leadership Theory. Hersey-Blanchard Situational Leadership Theory claims that successful leadership is dependent on picking the proper leadership style based on the followers' preparedness. Followers are eager and capable of doing a given duty. The hypothesis is relevant to the idea that leaders can provide and suffice for their employees' lack of talent and drive.

Path-Goal Theory. This concept is based on Ohio State's leadership research as well as the expectation theory of motivation. It requires leaders to provide followers with the information, support, or other resources they require to achieve their goals. This theory describes how leaders choose behaviors that are most suited to their followers' requirements and working environment in order to best assist their followers along their path and achieve the group's goals. The leader's job is to help followers achieve their goals by providing the necessary direction and assistance to ensure that their individual goals are in line with the organization's goals.

Leader-Member Exchange (LMX) Theory. In this theory, it is assumed that leadership is made up of various dyadic connections that link the leader to the followers. It also explains how leaders keep their positions in organizations. Leaders form connections with members that may either help or impede progress. Leaders naturally build relationships with their subordinates, and the strength of these relationships has a substantial effect on subordinates' accountability, judgment, resourcefulness, and individual performance.

With the ongoing pandemic, leadership in organization has a new and serious challenge. In the labor sector, contingency preparations are being made, such as looking for and discovering new ways to supply output and efficiently execute projects. All on- and off-site activities have been prohibited or curtailed for the safety of the employees and the community. Certain contingencies, such as work-from-home setup, skeletal staff structure, and tight application of health standards, have been used in companies in reaction to current initiatives carried out during a pandemic.

This has created a new and substantial challenge for managers and direct supervisors to function as leaders with their subordinates and coworkers. The bulk of work has been reduced or restricted as a result of this flexible and alternative manner of work arrangements, and challenges such as the following have arisen:

- $\quad$ Based on contingency theories of leadership, what is the most dominant style of leadership that Engineering Managers tend to conduct at the National Irrigation Administration - UPRIIS Division V?

- What leadership style is recommended to be utilized for National Irrigation Administration - UPRIIS Division $\mathrm{V}$ employees, in order for them to get motivated and promoted as future successful leader?

- $\quad$ Do the employees reflect the style of leadership utilized by the the National Irrigation Administration UPRIIS Division V's immediate leaders?

- How successful are these style of leadership utilized by the Engineering Managers of the National Irrigation Administration - UPRIIS Division V, and what influence do they have on inspiring and encouraging effective leadership among employees?

\section{MATERIALS AND METHODS}

A case study, as opposed to a comprehensive comparative analysis, is an in-depth examination of a specific research topic. It's frequently used to condense a large area of study into one or a few readily researched cases. According to Durrheim (2004:29), a research design is a strategic framework for action that acts as a link between research questions and research strategy execution. The researchers utilized a Descriptive Research design with a Quantitative technique to describe the leadership position in the National Irrigation Administration - UPRIIS Division V organization during the Covid-19 pandemic. Employees of the National Irrigation Administration UPRIIS Division V took part in this s tudy. The NIA division $\mathrm{V}$ is divided into areas such as operations, maintenance, engineering, administrative, and finance. It's also worth mentioning that the work arrangements are being put up with constraints, online settings, and limited interactions amongst coworkers. Developing a more flexible strategy for a leadership style that must be used and limiting the sampling procedure that can be employed.

The sampling method used is a voluntary response survey, which attempts to collect data from employees who have strong opinion about the issue of leadership styles. It is critical to have a sufficient sample size in 
order to obtain accurate and acceptable results. The researcher wants to collect data from as many people as possible from the whole population of the National Irrigation Administration - UPRIIS Division V office in Nueva Ecija. The researcher analyzed the data to reach a conclusion about the Effectiveness of the Engineering Manager's Leadership Style in National Irrigation Administration - UPRIIS Division V. The effectiveness of these leadership styles in terms of the professional growth of National Irrigation Administration - UPRIIS Division V employees. Finally, does the sort of workers reflect the leadership style of the National Irrigation Administration - UPRIIS Division V's direct leaders?

\section{RESULTS AND DISCUSSION}

Actual Leadership Style. The first objective of this case study is to determine the most dominant leadership style that Engineering Managers tend to perform in the National Irrigation Administration - UPRIIS Division V based from the contingency theories of leadership. The results on table 1 shows what are the most dominant actual leadership style that are being utilized in National Irrigation Administration UPRIIS Division V based on the Contingency Theories of Leadership.

Table 1. Actual Leadership Style based on Fiedler Model

\begin{tabular}{cc}
\hline Fiedler Model & $\begin{array}{c}\text { Responses (Total of } \\
\text { 25) }\end{array}$ \\
\hline Task-Oriented & $15(60 \%)$ \\
Leadership Style & $10(40 \%)$ \\
Relation-Oriented & \\
Leadership Style & \\
\hline
\end{tabular}

In times of a global pandemic, majority of the construction projects and activities in NIA have been restricted and there is a limited interaction between the Engineering Managers and their subordinates. It is shown in the tables 1 that Engineering Managers tend to be more task oriented. Different work arrangement have resulted to disorganization and improper allocation of tasks to the employees. It can be interpreted that most heads utilize task-orientation because of the need of organization and accomplis hment of pending tasks during the pandemic. Tasks are a way to measure the employees capability in their field of work. With the different work arrangements, some are conducted on a workfrom-home basis, it is easier to give tasks and focus on accomplishing it rather than being deliberately supportive on each of the employees. But a number of employees also mentioned that there are supervisors who are relationoriented. Which means there is a variety and balance of leaders between being task oriented and relationship oriented. Engineering Managers give tasks, but at the same time they are being supportive and gives motivation to their subordinates in finishing those tasks. It can be concluded that most utilize task orientation because of the need in organizing and accomplishing tasks, while some utilize relation-orientation because of unfavorable situations.

Table 2. Actual Leadership Style based on Situational Leadership Theory

\begin{tabular}{|c|c|}
\hline $\begin{array}{c}\text { Situational Leadership } \\
\text { Theory }\end{array}$ & Responses (Total of 25 ) \\
\hline Telling & $4(16 \%)$ \\
\hline Selling & $4(16 \%)$ \\
\hline
\end{tabular}

$\begin{array}{cc}\text { Participating } & 14(56 \%) \\ \text { Delegating } & 3(12 \%)\end{array}$

With the different variety of work arrangements and limited personnel present on site, giving a more participative and delegation of tasks became more difficult. However, it is worth noting that a number of employees see their Engineering Managers striving in having a participating leadership style. Which means they allow employees to take a more active participation to come up with ideas and make it a basis for the task and organizational decisions. As the pandemic is not a situation that one may expect, Engineering Managers tend to give employees the task of making decisions while being guided in those decisions.

Table 3. Actual Leadership Style based on Path-Goal Theory

\begin{tabular}{cc}
\hline Path-Goal Theory & Responses (Total of 25) \\
\hline Directive Leadership & $7(28 \%)$ \\
Achievement Oriented & $5(20 \%)$ \\
Supportive Leadership & $6(24 \%)$ \\
Participative Leadership & $7(28 \%)$ \\
\hline
\end{tabular}

Table 3 shows that there is a balance in the aspect of directive and participative when it comes to having a specific leadership style that best fits the employees and work environment to achieve a goal. Some employees see their Engineering Managers as someone who sets challenging goals yet directs it towards their needs and preferences. But a greater number of employees see their Engineering Managers as someone who consults and asks them before directing tasks and giving challenging goals. At the same time, there are those that observe directive leadership that let's employees know what is expected of them and tells them how to perform their tasks.

In summary, the most dominant leadership style is being task-oriented yet the tasks given are based through consulting with employees and asking for their suggestions before making a decision. They were given with the opportunity to be active in participating in the decision making process for the benefit of the organization. Although there are times where the Engineering Managers become simply directive, possibly because of unfavorable situation in work activities, and the only thing that could set it straight is a strict direct accomplishment of the task.

The second objective of the research is to determine the most effective leadership style based from what the employees of National Irrigation Administration UPRIIS Division V consider as an effective leader. The employees tend to be more motivated and active when the style of leadership being utilized is within their preferences.

Preferred Leadership Style. The second objective of the research is to determine the most effective leadership style based from what the employees of National Irrigation Administration - UPRIIS Division V consider as an effective leader. The employees tend to be more motivated and active when the style of leadership being utilized is within their preferences. 
Table 4. Preferred Leadership Style based on Fiedler Model

Fiedler Model Responses (Total of 25)

\begin{tabular}{cc}
\hline $\begin{array}{c}\text { Task-Oriented } \\
\text { Leadership Style } \\
\text { Relation-Oriented } \\
\text { Leadership Style }\end{array}$ & $13(52 \%)$ \\
\hline
\end{tabular}

With the recent turnout of events, global pandemic and mental health issues that engulfed the world. The employees preferred their Engineering Managers to be more focused on the tasks, as knowledge and methods on accomplishing it would help them. They believe that effective leadership is not just about having a positive relation with the supervisors, but rather it is also about how they will lead the workers to achieve their goals and objectives. Additionally, employees are sure that the leader gives them support and actually cared for their growth and development if they see that they are directing and delegating an organized task that they can follow to achieve their objectives.

Table 5. Preferred Leadership Style based on Situational Leadership Theory

\begin{tabular}{cc}
\hline $\begin{array}{c}\text { Situational Leadership } \\
\text { Theory }\end{array}$ & Responses (Total of 25) \\
\hline Telling & $1(4 \%)$ \\
Selling & $6(24 \%)$ \\
Participating & $15(60 \%)$ \\
Delegating & $3(12 \%)$ \\
\hline
\end{tabular}

It worth noting that only a little percentage of employees want to be delegated and only told with tasks. Delegating type of leadership give only a little attention for its members while telling just gives directions for tasks. Employees prefer having an active role in the working environment, at the same time they want to have someone to lead them. Although most of them have the ability, they know that they cannot do all things alone, but they want to have someone who will inspire them, give them motivation and direct them towards the goals and objectives. That's why they preferred having a participating type of leadership, or at least a balance between task and relation orientation in the working environment.

Table 6. Preferred Leadership Style based on Path-Goal Theory

\begin{tabular}{cc}
\hline Path-Goal Theory & Responses (Total of 25) \\
\hline Directive Leadership & $3(12 \%)$ \\
Achievement Oriented & $6(24 \%)$ \\
Supportive Leadership & $7(28 \%)$ \\
Participative & $9(36 \%)$ \\
Leadership & \\
\hline
\end{tabular}

Table 6 shows balance in the preference of the employees between supportive and participative leadership when it comes to leadership style based on their abilities and the working environment. Most of them still shows desire in a participative leadership as they prefer to be heard with their ideas, suggestions and feelings when decision making is at hand. While the least desire is on a directive leadership.

In summary, the preferred leadership style of the employees to be utilized by Engineering Managers have its focus on the tasks and have an active participation. They want to have someone to rely to about the procedures and tasks based on their needs and preferences. It shows their willingness to accomplish tasks if their leaders have the drive to allow them in the decision making process and have the initiative to accomplish tasks.

Maturity Level and Leadership Style. The third objective of the research is to determine if the type of employees matches the leadership style utilized by the Engineering Managers of National Irrigation Administration - UPRIIS Division V. The characteristic and traits of the employees give a significant factor to be considered on what leadership style should be utilized. Especially their abilities and willingness when it comes to performing tasks. The findings that we would want to focus is found on figures 5, 10, 11 and 12. And then compare it with the most dominant leadership style in National Irrigation Administration - UPRIIS Division to determine if it truly matches the needs and preferences of the employees.

Table 7. Maturity level of the Employees based on Situational Leadership Theory

\begin{tabular}{ll}
\hline $\begin{array}{l}\text { Situational Leadership } \\
\text { Theory }\end{array}$ & Responses (Total of 25) \\
\hline Unable and Unwilling & $0(0 \%)$ \\
Unable but Willing & $2(8 \%)$ \\
Able yet Unwilling & $1(4 \%)$ \\
Able and Willing & $22(88 \%)$ \\
\hline
\end{tabular}

Most of the employees identified themselves as someone who are able and willing. It means that they possess that skills, confidence and passion that is necessary to accomplish their works. Now the question is, does it match the leadership style being utilized by the Engineering Managers/supervisors based on the Situational Leadership Theory?

If the employees are able and willing, it means that they are ready for a delegating leadership style. Where most of the decisions come from the employees themselves, and the Engineering Managers' main job is to ensure that there is progress with them. But why does the employees prefer being in a Participative Leadership style rather than a Delegating one? The answer is because they prefer the participation process, where the employees and the Engineering Managers both work a balance on the decision. They still have the need to be guided and led. It is only logical to think that they prefer having their voice heard, but still needs confirmation from the people they look up.

Table 8. Characteristic of Two Sides Group according to

\begin{tabular}{lllc}
\hline LMX theory & & & \\
\hline $\begin{array}{c}\text { Leader } \\
\text { Member } \\
\text { Exchange } \\
\text { Theory }\end{array}$ & In Group & Unsure & $\begin{array}{c}\text { Out } \\
\text { Group }\end{array}$ \\
\hline $\begin{array}{c}\text { Performance } \\
\text { Rating }\end{array}$ & $19(76 \%)$ & $6(24 \%)$ & $0(0 \%)$ \\
$\begin{array}{l}\text { Attention } \\
\text { Treatment }\end{array}$ & $9(36 \%)$ & $12(48 \%)$ & $4(16 \%)$ \\
\hline
\end{tabular}

Based on the performance rating, most of the employees are sure that they are quite doing well. Based on the attention being given to them, the employees have 
different levels of attention being given to them by their Engineering Managers. Based on the treatment given to them, most of the employees feel being respected and treated as an essential member of the organization. These characteristics and situations are directly related with the Leader-member Exchange theory.

As most of the employees assessed that they perform better, given a considerable amount of attention and being as equal, we can conclude that most of the employees are being part of the group. It means that they belong to the In-Group of the Leader-member Exchange Theory. It means that most of the employees are trusted, receive disproportionate attention from the leader, and are more likely to be given special treatment when needed. They also have more job satisfaction, lower turnover, and better performance evaluations.

Effectiveness of Leadership Style. The last objective of the research is to determine the effectiveness of the leadership styles that Engineering Managers/supervisors in National Irrigation Administration used and what are its effect to motivating and promoting effective leadership to employees. From the survey, the Engineering Managers/supervisors were evaluated if their perform the most common functions of being an effective educational leader. At the same time, the employees were also asked to assess themselves if they think they possess these most common qualities of being an effective leader.

Table 9. Performance and Effects of the Engineering Managers' Leadership Style

\begin{tabular}{llll}
\hline $\begin{array}{l}\text { Engineering } \\
\text { Managers' } \\
\text { Leadership }\end{array}$ & Positive & Neutral & Negative \\
Style & & & \\
\hline Performance & 8.53 & 2.93 & 0.53 \\
& $(71.11 \%)$ & $(24.44 \%)$ & $(4.44 \%)$ \\
Effects & 10.13 & 1.86 & $0(0 \%)$ \\
& $(84.44 \%)$ & $(15.56 \%)$ & \\
\hline
\end{tabular}

The characteristics and traits that are being utilized by the Engineering Managers/supervisors come side by side with the leadership style they use. Which means its effect is in direct connection with the leadership style being performed. Table 9 shows that more than half of the employees experience and observe that their Engineering Managers/supervisors perform the common duties and responsibilities of becoming an effective leader. Additionally, there number of employees that are not sure that they have observed their Engineering Managers/supervisors to practice effective leadership in some situations. It is also worth noting that a very small percentage observed negative leadership and no employee have assessed that their Engineering Managers' leadership style resulted in a negative effect to them.

Positive effects outnumber positive performance in certain cases. Employees nonetheless manage to establish some leadership indicators, even if some leaders fail to demonstrate a positive performance in their leadership. For example, there are Engineering Managers who do not recognize, demonstrate, or put into practice the following signs of a successful leader: communication, inspiration, inspirational messages, role model, motivation, feedbacks, decisions, criticisms and weaknesses. Employees, on the other hand, have been able to experience similar impacts as a result of external variables such as their working environment, personal goals, and organizational dedication.

Other indicators have suggested that certain positive leadership performance is not yet emerging in the subordinates, and that they may require further effort to develop. The measures such as communication, being a role model, professional growth, motivation, accepting both positive and negative feedbacks, solving conflicts, and maintaining composure can be utilized by the Engineering Managers but some employees still fail to reflect it. Although the immediate has performed admirably on these indicators, they must encourage their subordinates to explore new opportunities and allow them to use both positive and negative feedback as prospects for improvement.

The findings suggest that the majority of employees perform well and that the leadership style has a favorable impact on both immediate leaders and employees. Only a few people believe they are not sure if they're improving or they are not improving at all. The data can be observed that approximate half fails to see the strengths and weaknesses of the employees, yet the employees are able to assess it themselves. This is evident in the employees' maturity level, since the majority of them are both willing and capable of completing jobs. Even if the members don't witness their leaders perform all of the effective leadership indicators for most of the time, with enough guidance and direction, they may progress on their own.

\section{CONCLUS IONS}

The most dominant leadership style is task-oriented, however the tasks assigned are based on communicating with employees and soliciting their feedback before making a decision. They were given the opportunity to actively participate in decision-making for the benefit of the organization. The findings also indicated that the preferred leadership style of the employees to be used by Engineering Managers has a focus on the tasks and an active participation. They want someone on whom they can trust for processes and chores that are tailored to their own requirements and preferences. It demonstrates their desire to complete activities if their well-being is prioritized.

The majority of the employees are deemed capable and willing. Furthermore, the majority of the employees assessed that they perform better, given a significant amount of attention, and being as equal as possible, we can assume that the majority of the employees are part of the group. It signifies they are part of the Leader-member Exchange Theory's In-Group. These findings imply that employees are ready for the immediate leaders to adopt a delegating leadership style. Delegating leadership is a style in which most decisions are made by the employees themselves, and the Engineering Managers' main role is to ensure that they are progressing.

Employees, on the other hand, prefer a Participative Leadership style over a Delegating one. The reason is that they prefer the participation procedure, in which employees and Engineering Managers work together to make a choice. They still require direction and leadership. It seems to reason that they desire to have their voices heard, yet still want validation from the individuals they 
look up to.

The effectiveness of a leadership style isn't just determined by the leader's attitude toward the traits. The working environment, the members' talents, their goals and preferences, and specific situations must all be taken into account. In order for a leader's leadership style to be effective, he or she must be able to discern what their subordinates' needs and preferences are. Each employee has different preferences and traits that must be developed in order to reach their full potential.

\section{RECOMMENDATIONS}

In terms of participation, the researcher first limited the s tudy to employees only in order to have a better knowledge of the efficacy of leadership styles from their perspective. A survey of Engineering Managers and administration should also be included in future study. Furthermore, when various groups are studied together, the level of participation varies substantially. More divisions, organizations and locale will have a better grasp of the effectiveness of the leadership style in use, employee preferences, and the effect on the employees' personal and professional development.

The survey approach was utilized in this study, and the majority of the questions were generic. Future research should include a more precise questionnaire as well as an indepth explanation from the employees. The purpose of this study is to compare current contingency theories of leadership to the actual practice being used from the employees' point of view. According to the poll results, there are various tasks and obligations of being an effective Engineering Managers and managers frequently fail to fulfill.

\section{REFERENCES}

1. Bass, B. M. (1990). From transactional to transformational leadership: Learning to share the vision. Organizational dynamics, 18(3), 19-31.

2. Burns, J. M. (1995). The crisis of leadership. The leader's companion: Insights on leadership through the ages, 8-10.

3. Farzad, A., Nahavandi, N., \& Caruana, A. (2008). The effect of internal marketing on organizational commitment in Iranian banks.

4. Fielder, F. E. (1964). A theory of leadership effectiveness. In L. Berkowitz (Ed.), Advances in experimental social psychology. New York: Academic Press.

5. Fielder, F. E. (1986). The contribution of cognitive resources to leadership performance. Journal of Applied Social Psychology, vol. 16, pp. 532-545.

6. Fiedler, F. E. (1967). A Theory of Leadership Effectiveness. New York: McGraw-Hill

7. F. E. Fiedler, M. M. Chemers, and L. Mahar (1977). Improving Leadership Effectiveness: The Leader Match Concept. New York: Wiley

8. Florencondia, N. T., Lansangan, R. M., Marcos, E. V., Santos, J. V., \& Soriano, K. R. (2021). New normal set-up on safety and health standards in government construction projects:A case of covid-
19. Regular Issue, 10(5), 370-374. https://doi.org/10.35940/ijeat.e2825.0610521

9. Graen, G. B., \& Uhl-Bien, M. (1995). Relationship-based approach to leadership: Development of leader-member exchange (LMX) theory of leadership over 25 years: Applying a multi-level multi-domain perspective. The leadership quarterly, 6(2), 219247.

10. Hersey, P. and Blanchard, K. H. An introduction to situational leadership. Training and Development Journal, vol. 23 (1969). pp. 2634.

11. Hickman, K.L. (2017). A Qualitative Study on Educational Leadership Styles and Teacher Morale. Carson-Newman University.

12. House, R. J. Path-goal theory of leadership: Lessons, legacy, and a reformulated theory. Leadership Quarterly, vol. 7 (1996). pp. 323352.

13. Hsu, H. Y. (2009). Organizational learning culture's influence on job satisfaction, organizational commitment, and turnover intention among R\&D professionals in Taiwan during an economic downturn. University of Minnesota.

14. Isaac, S. (2011). Teacher's Leadership Styles and Employees' Academic Performance in Mathematics Courses. University of Georgia.

15. Jamal, H., \& Shanaah, A. (2011). The Role of Learning Management Systems in Educational Environments: An Exploratory Case Study. Linnaeus University

16. Janse, B. (2019). Leader-Member Exchange Theory (LMX). Retrieved January 2, 2021 from toolshero:

https://www.toolshero.com/management/leadermemberexchange-theory-lmx/

17. Mtebe, J. (2015). International Journal of Education and Development using Information and Communication Technology (IJEDICT), 2015, Vol. 11, Issue 2, pp. 51-6. University of Dar es Salaam, Tanzania

18. Nguyen T. (2015). The Effectiveness of Online Learning: Beyond No Significant Difference and Future Horizons Vol. 11, No. 2, June 2015. Peabody College, Vanderbilt University'

19. Rautiola, J. (2009). The Effects of Leadership Styles and Student Academic Achievement. Northern Michigan University.

20. Rhode, J., Richter, S., Gowen, P., Miller, T., \& Wills, C. (2017). Understanding faculty use of the learning management system.Northern Illinois University

21. Schriesheim, C. A., Castro, S. L., \& Cogliser, C. 
C. (1999). Leader-member exchange (LMX) research: A comprehensive review of theory, measurement, and dataanalytic practices.The Leadership Quarterly, 10(1), 63-113.

22. Santos, J. V. L. (2021). Contingency Theories of Leadership: Effectiveness of the College Instructor's Leadership Style. EDUCATIO: Journal of Education, 6(2), 107-113

23. Santos, J. V., \& Gallardo, D. L. (2021). Ergonomic hazards in the workplace: Assessment, evaluation and prevention in the educational environment of Holy Cross College. International Journal of Multidisciplinary Research and Analysis, 4(07).

24. Santos, J., \& Jocson, J. (2021). A Comparative Analysis of Productivity Improvement Techniques in Educational Institution of Holy Cross College. Canadian Journal of Educational and Social Studies, 1(1), 14-32.

25. Smith, B. (2016). The Role of Leadership Style in Creating a Great School. Saskatchewan Education Leadership Unit.

26. Smith, G. (2017). Successful Instructional Leadership Styles In Education. Journal of Instructional Research, Volume 6. Grand Canyon University.

27. Verkerk, P. J. (1990). Fiedler's contingency model of leadership effectiveness : background and recent developments. (OCTO-report; Vol. 9002). Eindhoven University of Technology.

28. Yukl, G., \& Van Fleet, D. D. (1992). Theory and research on leadership in organizations 